\title{
Market structure and coherence of international cooperation: the case of the dairy sector in Malawi
}

\author{
Cesar Revoredo-Giha ${ }^{1 *}$ and Alan Renwick ${ }^{2}$
}

\author{
* Correspondence: \\ cesar.revoredo@sruc.ac.uk \\ ${ }^{1}$ Land Economy, Environment and \\ Society Research Group, Scotland's \\ Rural College (SRUC), King's \\ Buildings, West Mains Road, \\ Edinburgh EH9 3JG, UK \\ Full list of author information is \\ available at the end of the article
}

\begin{abstract}
A supply chain in disarray can be identified as a barrier not only to growth for the agricultural sector but also to achieving food security in a country because it may lead to either a deficiency in food production and/or too high prices. Using the dairy sector of Malawi as an example, the purpose of this paper is to discuss the coherence between market structure and the development strategy pursued by international donors. Within Malawi the dairy sector may be characterised as a segmented market: with both formal and informal milk markets, with smallholder producers serving both markets. The formal market includes few processing firms operating with idle capacity and selling dairy products to an affluent segment of the urban population, whilst the informal market comprises the sale of unprocessed milk products to the less affluent urban population and also rural areas. In this context, cooperative international action, conducted through agencies from a range of countries, is targeted at improving the efficiency of the formal supply chain and also the creation of local supply chains that sell processed products directly to poor consumers. The paper discusses reasons why these two cooperation strategies, given the structure of the sector, may potentially conflict with each other, the need to address the degree of market imperfection of the formal sector and the desirability of ex-ante coordination of plans amongst donors.
\end{abstract}

Keywords: Malawi dairy supply chain, Development economics, Industrial organisation JEL codes: $O, L$

\section{Springer}

\section{Introduction}

Supply chains in disarray have been identified in the economic literature as a barrier to growth for the agricultural sector (e.g., Gorton and White 2007). In addition, they can also be a constraint on the achievement of food security in a country, because less than the optimal amount will be produced with a given level of resources (therefore affecting the availability of food) and at higher prices (worsening accessibility and affordability of food).

There are various reasons for the malfunctioning of supply chains and in many cases there is an issue of path dependency. For example, this can be seen in the case of industries born from import substitution experiences (e.g., see Baer 1972 for a review of the Latin American case and Mytelka 1989, for the African case) or the corollary of those emerging from structural reforms such as in the case of the transition economies

(c) 2016 Revoredo-Giha and Renwick. Open Access This article is distributed under the terms of the Creative Commons Attribution 4.0 International License (http://creativecommons.org/licenses/by/4.0/), which permits unrestricted use, distribution, and reproduction in any medium, provided you give appropriate credit to the original author(s) and the source, provide a link to the Creative Commons license, and indicate if changes were made. 
(e.g., Gow and Swinnen 1998; Gorton et al. 2006). The consequence of these changes include, amongst others, supply chains that are plagued with problems of inefficiency, high transaction costs and unbalanced power distribution along the marketing chain (which can lead to important welfare implications for each of the supply chain participants). Cooperation from international donors can potentially help overcome some of these problems in a number of waysincluding the identification of problems (e.g., value chain analyses); knowledge transfer that aids innovation and; the provision of credit to supply chain stakeholders.

The purpose of this paper is to discuss the coherence between the market structure of a productive sector or supply chain and the support received from multiple donors, particularly when the latter is not coordinated. In this case, the efforts from multiple donors can pull the sector in different directions either neutralising the progress of the sector or slowing it down. The dairy sector of Malawi is chosen to highlight these issues.

Although Malawi is a small country, the Malawian dairy sector is an interesting case to study, because it has similar characteristics to the the dairy sectors of several SubSaharan Africa countries (Kurwijila and Bennett 2011) such as: the predominance of smallholding production; the existence of a formal supply chain that markets processed products (e.g., pasteurised milk); an informal sector that markets unprocessed products directly to poor consumers and; a processing sector (part of the formal supply chain) with significant idle capacity. In addition, Malawi has the lowest per-capita consumption of milk in Africa, estimated at $4.7 \mathrm{~kg} / \mathrm{capita} /$ year compared to an African average of $15 \mathrm{~kg} /$ capita/year (Imani Development Consultants 2004; CYE Consult 2009). In this context, different international donors, in apparently uncoordinated efforts, cooperate with the country, in two contrasting ways. On the one hand there is support for improving the formal supply chain through such activities as engaging in knowledge transfer and supplying micro credit. On the other hand, local supply chains are being encouraged through the donation of capital goods to dairy producer cooperatives in order to create local supply chains that can serve consumers directly with pasteurised milk instead of selling the milk to processors.

This paper discusses why, given the structure of the formal dairy sector, the two cooperation strategies are actually conflicting and ex-ante coordination of plans amongst donors would be desirable. Furthermore, the paper discusses why the underlying market structure is key in determining the optimal strategy to follow. On the one hand, if the sector is not perfectly competitive, then efforts aimed at strengthening the different stages of the formal supply chain (such as improving the efficiency of farmers) might fail in the longer run due to a lack of incentives (e.g., Alston et al. 1997). Under this situation, the strategy of creating local dairy supply chains might be appropriate in order to "discipline" the formal sector, forcing it to expand the production of processed milk, reduce dairy product prices and increase the demand for milk. On the other hand, if the formal sector is competitive but inefficient, the strategy of creating short dairy chains worsens the situation by further reducing the amount of milk available to processors, increasing their idle capacity and average costs.

The paper begins by providing background information on the Malawian dairy sector from production through to consumption, including a description of the cooperation work undertaken by the major donors in Malawi. Then, the methods are presented, 
starting with a brief explanation of why the two cooperation strategies discussed in the previous section may clash. This is followed by the presentation of the approach used to examine the presence of market power in the Malawian dairy sector. The next section, results and discussion, presents the estimation of market power and discusses the implications of the findings. Finally, some conclusions are drawn.

\section{Background}

The purpose of this section is to present an overview of the structure of the Malawian dairy sector. This is based on secondary information collected as part of a number of value chain analyses carried out as part of assessments required by international donors.

\section{Historical background}

Market-oriented milk production began in Malawi as a result of an increasing demand for liquid milk in the southern region of Malawi, mostly around the major towns of Blantyre and Zomba (see Fig. 1). This development led a group of farmers to import high-yielding dairy cattle from South Africa and Zimbabwe. Thus, for instance, between 1952 and 1954 more than 54 dairy cattle from European breeds were imported into the country and the commercial farms marketed milk directly to consumers. The first milk plant to pasteurise and market fresh milk in Malawi started operation in 1961 (Munthali et al. 1993; Chagunda 2009).

Intensive smallholder dairy production in Malawi only began in 1969 under a government initiative with the assistance of the Food and Agriculture Organization of the United Nations (FAO). The Malawian Government organised farmers into milk bulking groups $^{1}$ to operate as collection and checking centres, and established, through the Malawi Milk Marketing project, processing plants which were installed in the three major cities: Blantyre (1969), Lilongwe (1973) and Mzuzu (1974). In 1985, under a structural adjustment programme, the Malawi Milk Marketing project was reorganised and a statutory body, the Malawi Dairy Industries, took over the existing three dairy plants and three dairy farms and was given the mandate to operate commercially (Imani Development Consultants 2004).

In 1997, Malawi Dairy Industries were privatized. As a result, three private dairy processing companies were established in each region of Malawi: Dairibord (Blantyre), New Capital Dairy (Lilongwe), and Northern Dairy Industries (Mzuzu). In addition, two new private investors, Suncrest Creameries (Blantyre) and Lilongwe Dairy (Lilongwe) began dairy operations in 1998 and 2001, respectively.

\section{The supply of milk}

In Malawi, dairy production is performed on both smallholder and large-scale dairy farms. The major differentiating features of these two dairy sub-sectors are the holding size, the genotype of cattle raised, and the level of management applied.

The smallholder dairy sector is the largest subsector in the Malawian dairy industry, accounting for about 49,193 tonnes of milk in 2008, which is approximately $80 \%$ of the total milk production (Chagunda et al. 2006; DAHLD 2008). Furthermore, the 


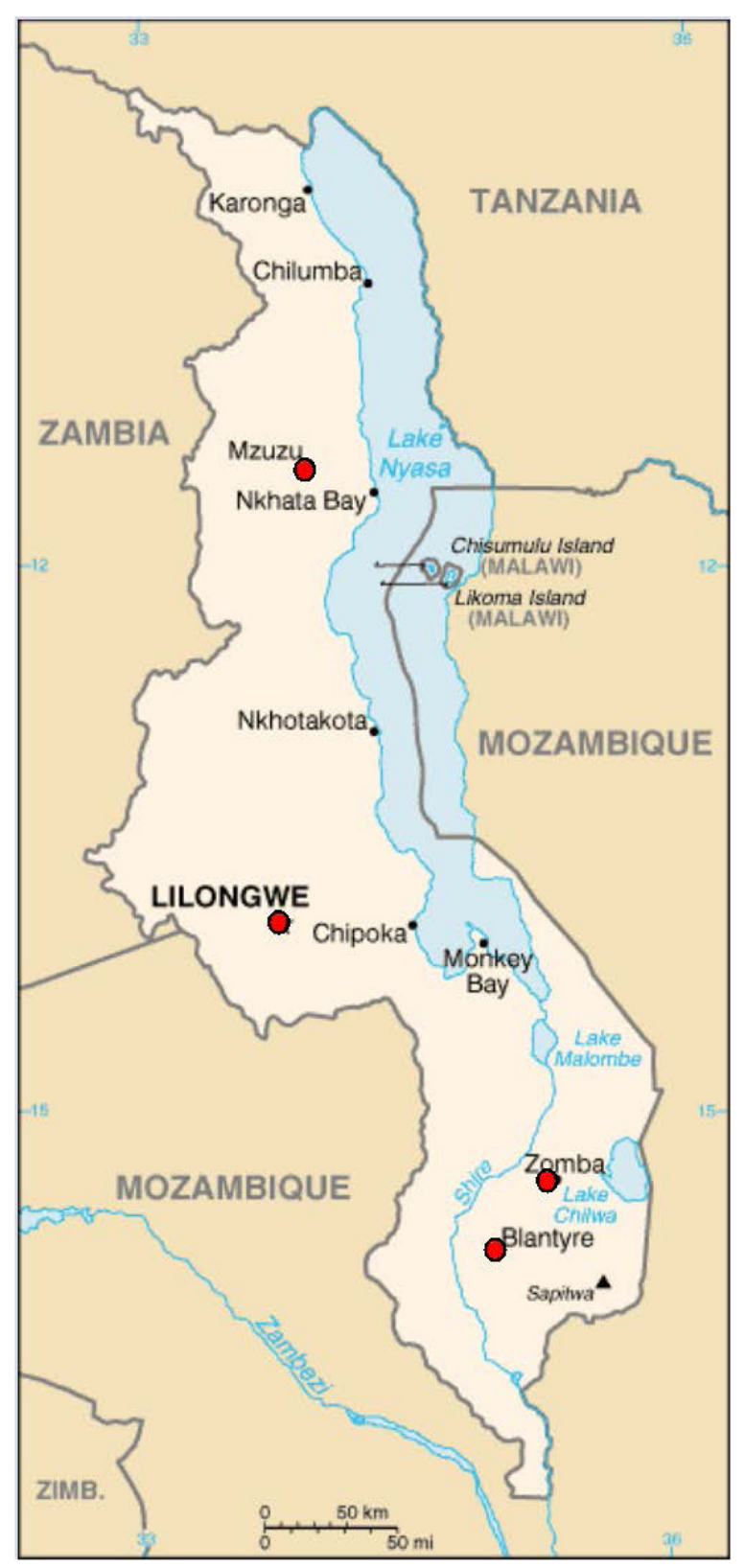

Fig. 1 Malawi map. Source: Buck (2008)

Government considers dairy production a priority within the livestock sector and supported the sector through a 5 year Heifer programme (Malawi Government 2008).

According to CYE Consult (2009) it has been estimated that $80 \%$ of the milk marketed in Malawi is produced in the Southern Region, $15 \%$ in the Central Region and $5 \%$ in the North Region. The production in the Southern Region has become more developed because land holdings are smaller than other parts of the country and dairy production offers a higher return per unit of land compared to other alternative options. Furthermore, dairy farmers with a small land area can make use of their crop residues, grass grown on uncultivated waste land and dambos (i.e., shallow wetlands) that are unused for crop production. Moreover, the Shire Highlands area (a plateau in 
southern Malawi, located east of the Shire River) is particularly suitable for dairy production because of its close proximity to Blantyre, the existence of good feed resources, a favourable climate and being relatively free of livestock diseases. The area has well developed milk collection network served by a reasonable road network system. There are other favourable milk producing areas in the country (e.g., in terms of climate, soils) such as the Viphya Plateaus (south of Mzuzu, Northern Region) or the Misuku Hills (Northern Region), but they suffer from isolation from any large urban areas, and are served with a poor road infrastructure system.

Non-governmental organizations (NGOs) such as Land O' Lakes with funding from USAID Small-scale Livestock Promotion Program, World Vision Malawi and Asian Rural-urban Development and Peace Institute (ARDEP) have incorporated dairy development in their rural programs. This has resulted in increased numbers of improved dairy animals. The predominant genotype on the large-scale dairy farms is the Holstein Friesian although some of these farms also have a few Jersey cows and other dairy breeds.

Despite the work done to improve the supply of milk, Fig. 2 (based on FAO data) shows that the domestic production response has been uneven. Between 1961 and 1987 production was trending upwards, however after this time the picture is much more uneven with periods of rapid production growth followed by dramatic falls. These falls have often been brought about by a reduction in the number of animals resulting from domestic food crises. This was particularly the case in 2002/03 and 2006/07. Since 2007 there has been a steady recovery in production, which is the result of increasing numbers of dairy cows and most recently by an improvement in yields as well. ${ }^{2}$

\section{The marketing of milk}

It should be noted that only a relatively small percentage of the milk produced domestically is destined to formal channels (i.e., the total milk undergoing pasteurisation) through the milk bulking groups.

According to CYE Consult (2009) milk collection first started near to Blantyre in the Shire Highlands and milk is now collected from a radius of 80 kilometres from the city. The Shire Highlands Milk Producers Association (SHMPA) in the Southern Region has

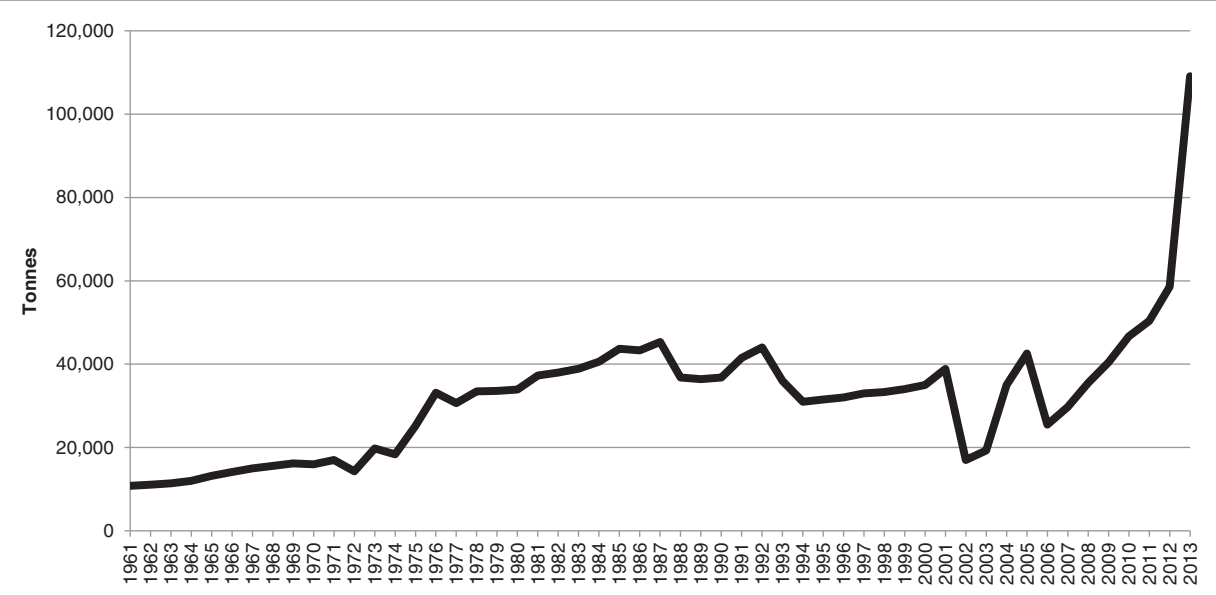

Fig. 2 Malawi: Production of milk 1961-2013 (tonnes) 
22 different milk bulking groups who on average (depending on the season), supply between 14,000 and 19,000 litres of milk daily to dairies in Blantyre and Lilongwe. Surrounding Lilongwe, there are 18 milk bulking groups who form the Central Region Milk Producers Associations (CREMPA), but CYE Consult estimated that only 10 were fully operational at the time of their study. Around Mzuzu, the Mpoto Dairy Farmers has 9 milk bulking groups.

Chitika (2008) estimated that about $19 \%$ of the milk produced was consumed on farm or wasted and the remaining $81 \%$ marketed either to the formal sector through milk bulking groups $(57 \%)$ or sold to vendors in the informal market $(23 \%)$. These percentages differ significantly from those produced by Imani Development Consultants (2004) who estimated that in 2004 the 6500 tonnes of milk reached the formal sector (16\% of total milk supplies, including imports) and 27,000 tons or $50 \%$ of total milk supply, including imports were destined to the informal market. ${ }^{3}$

According to Chitika (2008) the difference between his figures and those presented by Imani Development Consultants could be attributed to recent technical and financial support from organizations like Land O'Lakes and the Small Scale Livestock Promotion Programme (SSLPP) in selected milk bulking groups, who as a condition of this support prohibited farmers from supplying the informal market. If they did so they were at risk of risk losing their animals. This restriction only applied to farmers who accessed dairy animals from these organizations.

Chitika (2008) also explored the reasons why farmers were involved in the formal and informal markets. He argued that farmers sold milk in the formal market due to the fact that it assured market consistency and also smoothed consumption patterns. This is due to the fact that payments in the formal market are monthly, which acted as a form of savings mechanism in comparison to instant payments received in the informal channel. Three main reasons were given for the use of the informal market: higher prices than in the formal market ${ }^{4}$; access to cash quickly (through instant payment) and; low risk of non-sale, since no tests for milk quality were conducted.

The existence of a difference in the price received by farmers in the formal and informal market is an interesting feature of the milk market in Malawi. Imani Development Consultants (2004) estimated that the production cost for a litre of milk was between 14 and $16 \mathrm{MK} /$ litre as at March $2004^{5}$ for an average smallholder in the Southern Region. This cost of production, however, varies across different livestock management systems (e.g., smallholder versus estate) and between smallholders. The price paid in the informal sector was around $20 \mathrm{MK} /$ litre in the village when sold to institutional buyers. The base price for un-chilled milk paid by the milk bulking groups varied from 19 to $22 \mathrm{MK} /$ litre.

According to Chitika (2008) based on information from around 2007, the price offered in the formal channel was uniform, while that of the informal channel varied in different locations. Overall, the milk price per litre in the informal market ranged from MK 40 to MK 80 with a mean of MK just under MK 61. In the formal market the price was MK 44 per litre.

\section{Processing of dairy products}

The processing sector in Malawi currently comprises three major firms (Lilongwe Dairies, Dairibord Ltd. and Suncrest Creameries Ltd.) and two smaller (Katete Farms and 
MDI). According to CYE Consultants (2009) the processor New Capital Dairy has ceased operation). Table 1 presents data that combines information from Imani Development Consultants (2004) and CYE Consult (2009), who undertook a value chain analysis of several Malawian chains, including dairy, for the European Commission.

Table 1 shows that processing firms operate on average at about $30 \%$ of their capacity. ${ }^{6}$ This percentage though does appear to fluctuate as Imani Development Consultants (2004) indicate a range of between 20 and $40 \%$ of their capacity. This view that there is marked overcapacity is supported by Fintrac (2008) who estimate that Malawi's two largest dairy plants, Dairibord Malawi and Lilongwe Dairies, are operating under capacity, by 42 and $50 \%$, respectively. It should be noted that available measures relate to idle capacity in an engineering sense rather than, economic capacity which is determined by the optimal use of the resources, given input and output prices (see Winston 1974 for a discussion of this issue). ${ }^{7}$

An interesting feature of the processing sector, not uncommon in Africa, is that part of the milk that is domestically transformed into processed products is actually imported milk powder, which has been reconstituted (Fintrac Inc 2008). The amount of milk powder that it is imported varies from year to year, although according to Fintrac Inc. it is approximately 2000 MT per year. ${ }^{8}$

Imani Development Consultants (2004) reported that, circa 2003, processors paid the milk bulking groups around 20 to $22 \mathrm{MK}$ per litre but they noted that the price varied according to such factors as the volume collected, distance to the factory and a bonus system for the milk bulking groups etc. During the same period, imported milk powder was landed in Malawi at a price of $27 \mathrm{MK}$ per litre (reconstituted) (i.e., at least $30 \%$ more expensive than domestically collected milk ${ }^{9}$ ). Liquid pasteurised milk was sold to retailers at around MK 50 per litre and to the final consumer at around MK 60 to 62 per litre.

Information from CYE Consultant (2009) reported that in 2008 the prices being offered for fresh milk by the main processors had improved. Suncrest Dairies in Blantyre paid producers MK 52 per litre and Lilongwe Dairies bought milk in the Central and Southern Regions at MK 55 per litre, while the Blantyre based Dairibord also increased its own price to MK 55 per litre. However, because there was little competition in the Northern Region for processed milk, Northern Dairies paid only MK 40 per litre.

Table 1 Production capacity and utilization major dairy processors, 2012

\begin{tabular}{lllll}
\hline Company & Location & $\begin{array}{l}\text { Production } \\
\text { Capacity } \\
\text { Thou. It/day }\end{array}$ & $\begin{array}{l}\text { Idle } \\
\text { Capacity 2012 } \\
(\%) ~ 1 /\end{array}$ & Main dairy products \\
\hline Dairibord Ltd. & Blantyre & 40 & 61 & $\begin{array}{l}\text { Pasteurised Milk, Flavoured } \\
\text { Yoghurt and Chambiko }\end{array}$ \\
Suncrest Creameries Ltd. & Blantyre & $25-30$ & 76 & $\begin{array}{l}\text { Pasteurised and Steri Milk, } \\
\text { Drinking, Yoghurt }\end{array}$ \\
Lilongwe Dairies & Lilongwe & 75 & 63 & $\begin{array}{l}\text { Pasteurised Milk, } \\
\text { Katete Farms }\end{array}$ \\
MDI & Lilongwe & 10 & 77 & $\begin{array}{l}\text { Plavoured) Yoghurts } \\
\text { Lilongwe }\end{array}$ \\
\hline
\end{tabular}

Source: SHMPA and CREMPA data (2012); Imani Development Consultants (2004); CYE Consult 2009 Notes. 1/Own estimation based on milk deliveries data from SHMPA and CREMPA 
Untreated and often diluted milk is sold by vendors directly to consumers at about MK 50 per litre. Consumers are paying in supermarkets between MK 70 to 100 per litre for pasteurised milk.

Figure 3 provides the monthly evolution of milk price paid to farmers and highlights that the nominal price is characterised by discrete adjustments, after which it remains constant. In contrast, the real price shows a long term negative trend showing decreases in purchasing power due to inflation.

Little information is available on the actual processing costs of milk in Malawi. According to Imani Development Consultants (2004) these vary by product and generally, the less the value added the less the processing cost. The margin is also related to the added value. According to the processors, the net margin on liquid pasteurised milk is as low as $5 \%$ whereas this can be as high as $15 \%$ for products which have higher added value such as cheese. For these products a much higher gross margin was reported, but due to high operational costs, especially electricity, water and transport costs within Malawi, the net margin is estimated at between 3 and $10 \%$. Supermarkets are reported to take a margin of 15 to $20 \%$. According to Imani Development Consultants the processing sector attains profits despite its high costs by targeting the affluent part of the urban population.

\section{Trade in dairy products}

CYE Consultant (2009) report that due to low internal demand, value added products such as cheese, yoghurt and butter are imported to satisfy the demand that exists. However, whole dried milk (i.e., milk powder) and UHT milk are by far the major imported products in the dairy sector. Figure 4 presents the imports of whole dried milk.

On a milk-equivalent-basis imports have a dominant role in the market and exceed the formal local market supply by a substantial margin (75\% versus $25 \%$ circa 2008) even though imported milk is more expensive than locally produced. The source of imported milk products depends very much on world prices and also on which part of the world is generating surpluses. At present cheese and yoghurts are coming from South Africa, butter from Zimbabwe and powdered milk from Ireland and New Zealand.

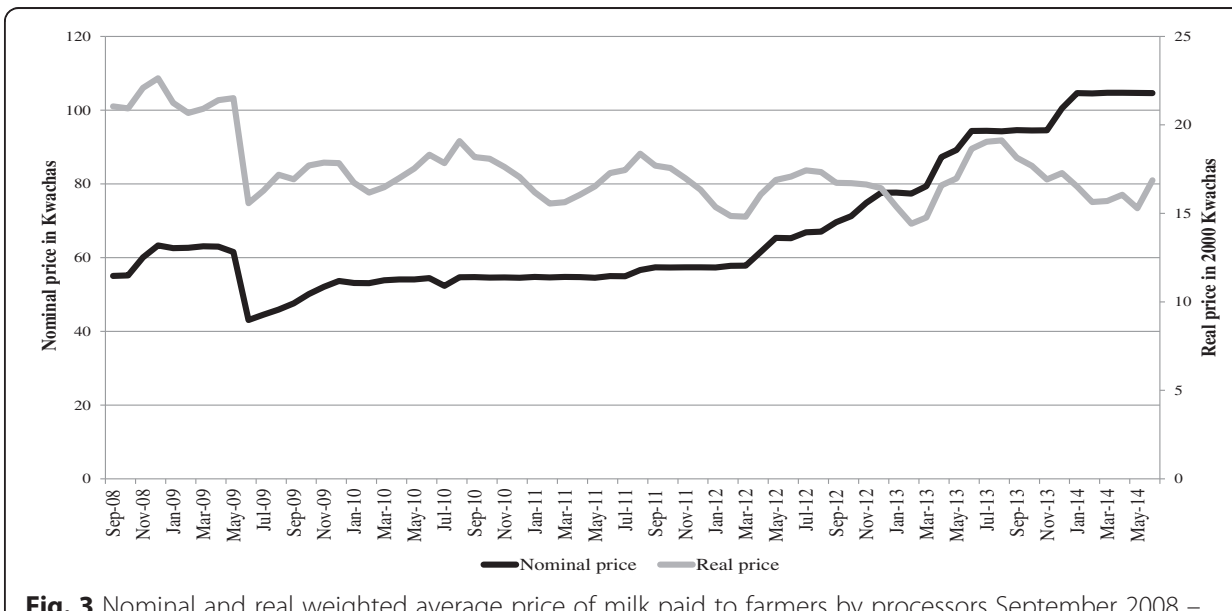




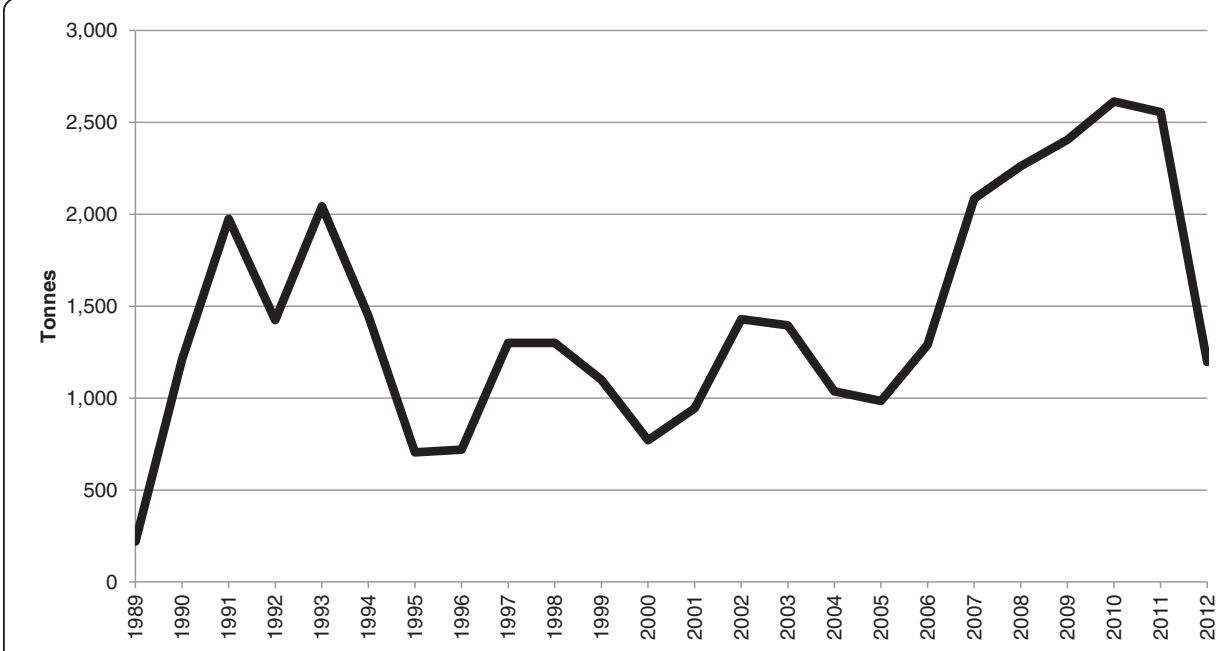

Fig. 4 Malawi: Imports of whole dried milk 1988-2012

\section{Consumption and distribution of dairy products}

Compared to the rest of Africa, the consumption of milk products in Malawi is very low, which is caused mainly by low purchasing power, limited supply and poor distribution beyond the main urban and trading centres (CYE Consultant 2009). In fact, according to Imani Development Consultants (2004), Malawi has the lowest consumption of milk per capita in Africa estimated at $4.7 \mathrm{~kg} / \mathrm{capita} /$ year compared to an Africa average of $15 \mathrm{~kg} /$ capita/year (CYE Consultant (2009) estimate these figures as 4 and 20 litres per capita, respectively).

Historically in Malawi, most consumers used powdered milk and where fresh milk is unavailable or is inconvenient to buy, powdered milk still forms the main form of milk consumed. Fresh pasteurised milk has traditionally been sold only to the higher and middle income groups.

Sales and consumption of milk is heavily concentrated in the urban areas. The retail sector is dominated by the large supermarkets such as People's Trading Centre (PTC) and Shoprite. Besides large supermarkets, milk is also sold by small convenience stores, informal shops in low income housing areas, vendors and trading stores outside of the three main cities. It has been reported that selling to retail outlets gives the highest profit margin to processors, due to the fact that the milk can be sold to them in bulk.

In addition to processed liquid milk there is also a considerable supply of milk powder in tins and packets in urban areas. The tins tend to be sold in the bigger stores that are targeting upper and middle-income consumers, whilst the packets and sachets are sold in smaller retailers targeting lower income consumers. Milk powder is very important to smaller retailers, because many of them do not have refrigeration facilities. It is though interesting to note that small retailers are able to sell milk at the same price as the large retailers.

As pointed out in Chitika (2008) studies have shown that informally marketed milk is associated with zoonotic health risks (which include brucellosis, coliforms and bovine tuberculosis) and high bacteria counts which are due to poor hygiene and a long time lag between milking and sale. The absence of pasteurization increases the risk posed by such organisms. There is therefore a need for effective control measures including 
hygienic handling of milk and its pasteurization to protect public health. However, actual health risks from bacterial contamination are judged to be low because of the common consumer practice of boiling milk before consumption.

Information on how the consumption of dairy products in Malawi reacts to changes in expenditure and prices is limited. Although, Ecker and Qaim (2011) estimated expenditure and Marshallian own price elasticity for food products using the 2004-05 Living Standards Measurement Survey for Malawi. Their results for milk and dairy products are presented in Table 2. On average, urban consumers react more to changes in expenditure but less to prices than rural consumers. Furthermore, the income elasticities indicates that milk and dairy products are "luxuries" for the urban population while "necessities" for the rural population. The reason for these differences are not clear and deserve further research as they might be due to the aggregation amongst several different type of products of different qualities.

\section{International development donors in the dairy sector in Malawi}

Dairy is considered a key investment sector within agriculture for the Government of Malawi (MIPA 2011) and donors such as the USA (through USAID, United States Agency for International Development), Japan (through JICA, the Japan International Cooperation Agency) and Belgium (through FICA, the Flemish International Cooperation Agency) have focused part of their development aid on the sector (in the case of USAID this has been with the participation of the Land O'Lakes firm since 1999).

According to Imani Development Consultants (2004), donor support has assisted the Government in the goal of meeting its stated objectives of development of the dairy sector, namely: to promote dairy production so as to achieve self-sufficiency in dairy and dairy products; to exploit export markets when surpluses arise; to contribute to welfare of Malawians by providing dietary animal products and; income generating activity through higher levels of production and competitive marketing systems.

The purpose of this section is not to provide a detailed description of all the work that different donors are carrying out in the dairy sector in Malawi, but through the description of two different work programmes in the country, highlight two different development strategies pursued by donors. The first strategy can be portrayed under the tag of "Strengthening the formal dairy sector" (as exemplified by the USAID support through the work undertaken by Land O'Lakes) while the second strategy can be classified as "Development of local supply chains" (identified with work supported in Africa by the JICA).

\section{"Strengthening the formal dairy sector" strategy}

Under this strategy we briefly consider the main characteristics of the work of three donors: USAID through Land O' Lakes; the EU support through their involvement with the Shire Highland Milk Producers Association and; the work supported by FICA.

Table 2 Consumer's expenditure and Marshallian own price elasticities for milk and dairy products

\begin{tabular}{|c|c|c|c|c|c|c|c|c|}
\hline \multirow[t]{2}{*}{ Elasticities } & \multicolumn{4}{|l|}{ Rural } & \multicolumn{4}{|l|}{ Urban } \\
\hline & Average & Lowest & Middle & Highest & Average & Lowest & Middle & Highest \\
\hline Expenditure & 0.870 & 0.877 & 0.868 & 0.849 & 1.514 & 1.580 & 1.599 & 1.079 \\
\hline Price & -0.746 & -0.509 & -0.691 & -0.827 & -0.551 & -0.542 & -0.627 & -0.564 \\
\hline
\end{tabular}

Source: Ecker and Qaim (2011) 
The Land O'Lakes dairy sector development programme USAID sponsored the Land O'Lakes' dairy sector development program, which started in 1999. According to Land O'Lakes (Buck 2008) the goal of this project was to increase rural incomes by increasing the number of rural poor households deriving their main livelihood from dairy business, through managing high productivity enterprises, while delivering improved quality and affordable dairy products to the market. The total investment in the sector was US\$ 11.0 million, of which US\$ 2.5 million were USAID direct investment plus US\$ 8.5 million in leveraged funding.

Their key project components comprised: development of efficient milk producer organisations; development of efficient dairy processing and marketing and; expansion of effective industry support services.

Their development strategy can be described as being based on the results of value chain analyses of the dairy sector. Buck (2008) highlights the following specific aspects of these analyses:

a. Milk quality - Their diagnosis is that milk is of poor quality, not meeting international standards and there is a lack of certified laboratories. Therefore, their programme promotes milk traceability systems and services and facilitating upgrading of laboratory methods and equipment.

b. Supply - They found seasonal variation in production associated with the dry season and lack of availability of forage and pasture seeds. In response to this, the programme promotes use of water development and silage making services and action-oriented research into new seed varieties.

c. Policy - They considered that the sector had inadequate animal feed quality standards and that the industry associations have limited resources, so they propose to facilitate technical revisions to and advocacy for enactment of animal feedstuffs act and to facilitate capacity building of the associations to increase revenue collection and service provision.

d. Market - They found that export requirements were not well understood by the industry and there was low per capita milk consumption. Their programme proposed stimulating the export market facilitation services and facilitating industry-led consumer awareness campaigns to promote purchase of quality milk.

e. Producers - Their value chain analysis found that producers had high cost and use poor quality commercial feeds. In addition, they lacked access to appropriate financial services. Therefore, their programme promoted the use of improved feed formulation and testing services and the innovative delivery of financial services and development of new financial products.

f. Milk bulking groups - They found milk losses due to lack of cold chain infrastructure and lack of guaranteed market for members' milk. Their strategy to address this consisted of facilitating links to financial service providers and promoting guarantee schemes with processors. They also proposed to facilitate vertical linkages and promote use of supply contracts between the milk bulking groups and the processors.

g. Processors - The value chain analysis found that the quality of processed milk was not aligned with export standards and that they suffered of margin squeeze affecting profitability. They proposed to promote quality assurance services and to 
increase access to market information and the link to business sector programmes to develop higher-value products and markets.

h. Inputs and Services - For this stage of the chain they found that there was a lack of awareness of financial service options and that the return on investment of providing in-house services and/or inputs was low or unknown. As a result, they proposed to encourage financial service providers to expand marketing of existing and development of new financial products and to promote feasibility studies and pilot programmes for new, innovative services, inputs and technologies.

Finally, in order to develop a sustainable dairy sector support system, Land O'Lakes stated its intention was 'to source local and regional training and technical providers to assist in the development of the sector including a strong emphasis to be placed on the integration of the current local dairy service providers into the project'.

The shire highland milk producers association The Shire Highlands Milk Producers Association (SHMPA) is a farmers' organisation established in 1985 to look after the interest of smallholder dairy farmers in the Southern Region. It has a membership of 2900 dairy farmers who sell their milk through the SHMPA managed milk collection network. This network consists of 20 milk bulking groups within an $80 \mathrm{~km}$ radius of Blantyre According to Imani Development Consultants (2004) the main funders of the project were the EU and Oxfam.

The activities carried out by the SHMPA include: milk collection centre maintenance; establishment of new collection centres; provision of AI services; election and training of milk bulking group committees; auditing of milk bulking group accounts; advocacy for smallholder dairy farmers - especially concerning milk marketing, input supply and field services; farmer training in dairy farm management; operating a heifer loan scheme; heifer breeding for new farmers and; provision of sustainable farmer-managed animal breeding and health services.

In addition to the resources from donors, all farmers pay a small levy on milk sold to cover the costs of SHMPA's activities. SHMPA's activities have had a positive influence on dairy farming in the Southern Region as they also help farmers to establish dairy farms under the Heifer loan scheme and provide field extension services (Imani Development Consultants 2004).

Flemish international cooperation agency In 2009 the Flemish government awarded the Malawi Milk Producers Association the sum of $€ 500,000$ for a four year project (FICA 2011). The objective of the project is to strengthen the dairy sector in the central and northern regions of Malawi by targeting four areas: capacity building and training of the farmers and the milk bulk groups; reinforcing the capacity of the associations; improving the technical services and; increasing the cattle numbers.

By targeting the direct link between farmers and the milk bulking groups, the objective of the project is to raise milk production from its current low level, through adequate training and management. Furthermore, existing farmers as well as potential new entrants into dairying will be educated in marketing, hygiene and quality control. 
At an institutional level, the associations' staff members are trained to improve management practices with the aim of achieving sustainability of the associations. This means among other things general and financial management, leadership, marketing, etc. One important task of the associations is to provide information to their members on the wellbeing of the animals, nutrition, artificial insemination, barn construction, etc. Through bundled purchase of inputs, such as seeds, by the regional associations, the associations can ensure that the farmers will pay less than if they were negotiating individually and in time the association will be able to operate independently that way. It is reasoned that a well-run association that provides professional services will gain more members and farmers can continue to make the change from informal dairy production to a more formal dairy production.

\section{"Development of local supply chains" strategy}

The approach followed by JICA is analysed in Kurokawa et al. (2008) ${ }^{10}$ and has many aspects in common with the strategies already reviewed, as it is also focused on the development of the private sector in Africa. The strategy is known as a One Village One Product (OVOP) approach and is based on a "strategic movement" which relates closely to regional development policies. It has its origins in Oita, one of the 47 prefectures of Japan. It began in the 1970s as a community-based business activity aimed at rediscovering and revitalising economically backward rural areas. The movement was introduced in 1979 by former governor of the Oita Prefecture in Japan, Dr. Morihiko Hiramatsu. Under the OVOP movement each village is encouraged to produce at least one product or service which can be showcased across the country and the world (Kurokawa et al. 2008, p. 23).

JICA considers that the major constraints on the performance of SMEs include costs and access to finance (considered the major resource constraint), access to electricity, corruption, tax administration, level of skills and transportation. Furthermore, they consider that many of the binding constraints are due to the presence of market and government failures, which justifies support for private sector development. The OVOP approach is located at the micro end of the spectrum of donor activities since it aims to provide specific support for individual firms, groups of firms and/or households.

The OVOP programme in Malawi is relatively small with an investment of $\$ 500,000$ supporting four dozen projects. The programme aims to develop products and services through value adding by communities and using locally available resources in a designated area. Specifically, it aims to: promote the OVOP concept approach of economic development at the level of villages; promote value adding technologies, such as agroprocessing, quality control and packaging, at the village level; to facilitate small-scale business skill development at the village level; to promote market linkages between products and services from villages and domestic/international markets.

As pointed out by Kurokawa et al. (2008) the Malawi OVOP Programme had at the time of the study supported 46 projects for 12,943 beneficiaries, including activities on: dairy processing; fish processing; vegetable production and processing; rice milling; honey production and mushroom production. One group, for example, received technical support from the programme and built a multi-purpose model factory where 
members successfully managed to produce commodities like confectionary, cooking oil, and milk from soy beans and other products. Some of the OVOP products have been exported to South Africa and Japan.

The Bvumbwe Milk Cooperative, formed in 2003, was one of the first projects to be funded by OVOP. Bvumbwe received a loan of around US\$12,000. JICA helped dairy farmers in Bvumbwe who had a milk bulking group to form a cooperative. It also procured a cooling tank which the cooperative uses to store its milk before it is sold to the Dairiboard, the largest consumer of raw milk in Malawi.

It should be noted that under the OVOP programme the Bvumbwe Milk Cooperative has improved productivity and reduced the loss of milk collected from its members. Milk production has increased from 13 litres to 27 litres per animal per day. The establishment of the cooperative has made it possible for them to negotiate with Dairibord better prices as the quality of milk produced is of a high standard. This has also led to an increase in the number of farmers and animals in the cooperative, increasing from 12 to 117. JICA supplied the Bvumbwe with a milk pasteuriser and milk packaging machine in 2003 for the cooperative to sell milk directly to consumers and not through the major milk companies (One village one group (OVOP) 2011).

\section{Methods}

The purpose of this section is to present the methods to be used in the paper. However, before presenting the specific method used it is important to understand: first, why the two approaches followed by the donors for the Malawian dairy supply chain potentially conflict, and; second, why the choice of strategy to follow is dependent on the nature of competition within the sector, that is whether it is perfectly competitive or whether the processing sector has the capacity to exercise market power.

\section{Why the two strategies potentially conflict}

From the review of the donors' strategies it is clear that they pursue similar goals, which can be represented by Fig. 5. Panel a of the figure represents a stylised version of the current consumption market for milk, ${ }^{11}$ which can be classified into high quality demand and supply for milk (denoted by the supra-index $\mathrm{H}$ ) and low quality demand

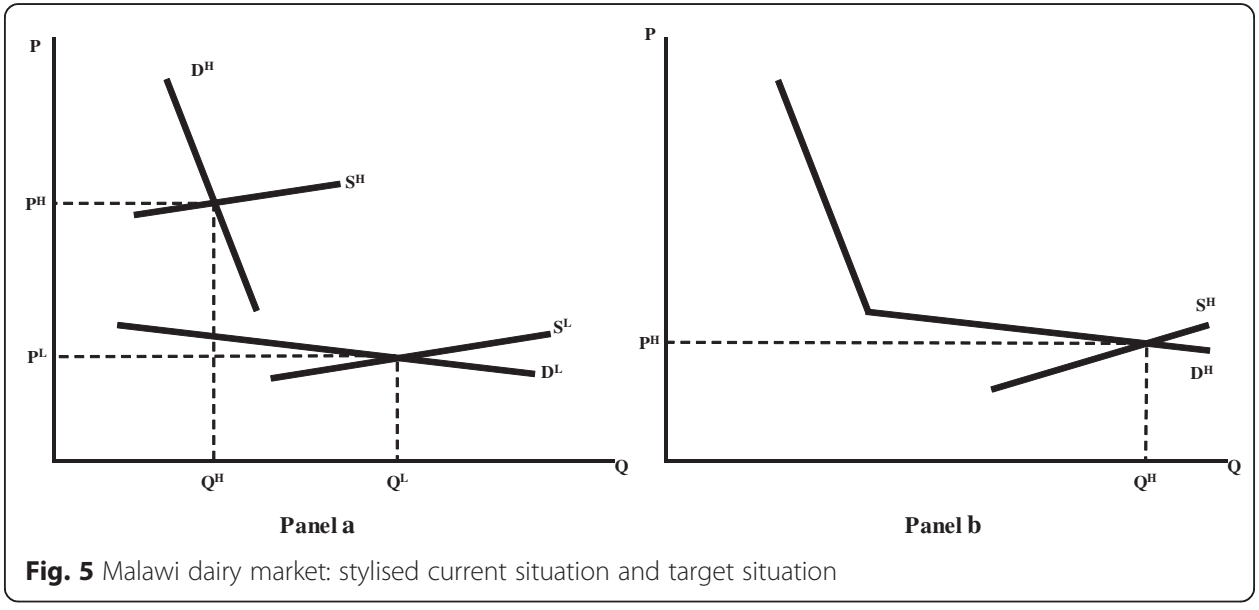


and supply for milk (denoted by the supra-index L). As shown in the figure the formal sector sells a low quantity of high quality milk (i.e., pasteurised) at a high price, while the informal sector sells a large quantity of low quality milk at a lower price than the formal sector (note that this is at the retail level). The presence of two demand curves is due to the fact that the population can be considered as segmented by income, so the high quality milk is sold to the affluent urban group and the low quality milk is sold to the rural and poor urban population. Panel $b$ of the figure can be considered as the situation targeted by the donors, as the high quality milk replaces the low quality milk and the supply expands sufficiently to serve both the rural and urban population. Of course, the difference between the two strategies discussed in this paper is in how to move from the situation in Panel a to Panel b.

It is clear from the review of the donors' strategies that they have a great number of features in common, such as increasing the efficiency of milk producers though micro credit, knowledge transfer, empowering producers organisation, etc. Therefore, we focus on those aspects that may lead to conflicts between the two approaches.

Overall the comparison between the two strategies can be seen as two different views of what to do with an ineffective/inefficient supply chain. On the one hand, the strategy of strengthening the formal dairy sector followed by USAID and others is aiming to revamp a supply chain that it is in disarray and their strategy involves the entire supply chain. On the other hand, JICA's OVOP strategy aims at creating local supply chains that sell processed milk directly to consumers, bypassing the formal sector. Furthermore, their strategy does not, to our knowledge, encompasses supply chain stakeholders beyond the producers (and of course their associations).

At the most direct level of comparison both strategies are actually in conflict with each other because a key feature of the formal dairy sector is the presence of significant excess capacity in processing that appears to arise because of the low supply of milk to the processing sector. The aim of USAID and the other donors' strategy is to expand that supply of milk, while JICA's strategy of supporting direct marketing of pasteurised milk to consumers worsens the situation by reducing the supply of milk to processors and increasing their level of inefficiency.

A more substantive comparison involves considering each strategy as an approach to development. On the one hand, the USAID and others are betting on a formal sector that can be strengthened to replace the unsafe informal market and satisfy an undernourished population with safe dairy products at affordable prices. On the other hand, JICA's strategy implies (though it should be noted that this is not explicitly stated) bypassing the ineffective formal sector to create a local supply of safe dairy products at affordable prices that can replace the informal sector.

It may be argued that which of these strategies is most appropriate for the development of a dairy sector in Malawi, will depend in great measure, on whether the dairy sector is a competitive one, i.e., whether the processing sector (and also the retail sector) has market power. ${ }^{12}$

For example, if the processing sector is not competitive, then, all the work of USAID and others to expand the supply of milk might be wasted as producers will continue to receive low prices for their milk, the supply of high quality milk will still be insufficient for the population, affluent urban consumers will continue paying high prices for their milk and the informal market will remain. In this context, JICA's strategy might be 
appropriate because it will not only ensure the expansion of the supply of high quality milk but also "discipline" the non-competitive processing sector and force them to expand to compete.

On the other hand, if the processing sector is competitive but inefficient, JICA's strategy worsens the situation by reducing the amount of milk available to processors due to encouraging direct marketing of milk and investment should be directed at revamping the processing industry together with expanding domestic milk production.

In the next section we consider the issue of market power in the Malawian formal dairy sector in more detail.

\section{Measuring imperfect competition in the Malawian dairy sector}

It should be noted that in the absence of statistics to test the degree of market power, we take a simpler approach using secondary data collected as part of a number of value chain analyses and use the approach suggested by Landes and Posner (1981) for cases of market power in antitrust cases.

\section{Processors' potential oligopoly power}

While it is not possible to estimate the degree of imperfect competition due to the lack of readily available time series, it is possible to explore the degree of market power of the processing companies by estimating the Lerner index (L) for each firm based on secondary information provided in the value chain analyses. Thus, in this paper we follow the approach by Landes and Posner (1981) of computing the L for a dominant firm. The $\mathrm{L}$ for a firm $\mathrm{i}$ is given by:

$$
\mathrm{L}=\frac{\left(\mathrm{P}-\mathrm{MgC}_{\mathrm{i}}\right)}{\mathrm{P}}=\frac{1}{\varepsilon_{\mathrm{i}}^{\mathrm{d}}}
$$

Where $\mathrm{P}$ is the output price, $\mathrm{MgC}_{\mathrm{i}}$ is the marginal cost of the firm $\mathrm{i}$ and $\varepsilon_{\mathrm{i}}^{\mathrm{d}}$ is the absolute value of the demand elasticity faced by firm i (i.e., elasticity of the residual demand defined as $Q_{i}^{d}=Q_{m}^{d}-Q_{j}^{s}$, where $Q_{m}^{d}$ is the total demand and $Q_{j}^{s}$ is the total supply of all the competitors to firm i (i.e., j firms). Differentiating the residual demand for $i$ with respect to the prices and transforming the expression into elasticities and shares, one obtains the expression for the elasticity of the residual demand faced by firm i, which is given by (2):

$$
\varepsilon_{\mathrm{i}}^{\mathrm{d}}=\varepsilon_{\mathrm{m}}^{\mathrm{d}}\left(\frac{1}{\mathrm{~S}_{\mathrm{i}}}\right)+\varepsilon_{\mathrm{j}}^{\mathrm{s}} \frac{\left(1-\mathrm{S}_{\mathrm{i}}\right)}{\mathrm{S}_{\mathrm{i}}}
$$

Where $S_{i}$ is the market share of firm i defined as $Q_{\mathrm{i}}^{\mathrm{d}} / Q_{\mathrm{m}}^{\mathrm{d}}, \varepsilon_{\mathrm{m}}^{\mathrm{d}}$ is the market demand elasticity and $\varepsilon_{j}^{s}$ is the supply elasticity of firms $\mathrm{j}$. The strategy to estimate $\mathrm{L}$ for each firm consists of replacing in the formula the estimated demand shares and elasticities.

\section{Processors' potential oligopsony power}

Due to the lack of information on the informal market, it is even more difficult to provide a measure of the degree of market power in the input market (i.e., milk). Therefore, the approach adopted here consists of using available statistics and evidence provided by Revoredo-Giha et al. $(2013,2015)$ to inform the discussion. 


\section{Results and discussion}

The purpose of this section is to present the results of the analysis and discuss whether the formal dairy sector in Malawi operates in a non-competitive way: first, with respect to urban consumers paying high prices for the dairy products (oligopoly) and with respect to producers receiving low prices for the milk (oligopsony). As mentioned, due to the lack of available data for the dairy sector, the analysis has been carried on based on the available information arising from value chains analyses that have been carried out for the sector. ${ }^{13}$

It is important to mention that the degree of competition in the dairy market has been mentioned in the value chain analyses, but only in a marginal way. For instance, this can be illustrated with reference to the report by Kedrock and Agar (2007) for USAID, which indicates that "the three operating medium processors are reportedly profitable while running at only $20-35 \%$ of capacity utilization. This is possible because they target the top $3 \%$ of the population (375,000 people) with the highest disposable income that are relatively price insensitive. This conservative approach removes a good portion of the risk, but it does limit growth and volumes" (Kedrock and Agar 2007, p. 32). The same authors also state that "Processors also are reported to pay low prices for raw milk" (Kedrock and Agar 2007, p. 30). Despite that evidence the same authors indicate that while the formal processing level is highly concentrated, "it appears to be reasonably competitive. The production level is fairly well organized through associations and MBGs. Milk moves from source to processor and consumer fairly effectively, if not always efficiently, though it is not uncommon for tankers of milk to be lost from non-collection due to poor roads and breakdowns" (Kedrock and Agar 2007, p. 32).

Based on the above arguments it is easy to see why market imperfection may fit the stylised facts that were described in the overview of the Malawi formal dairy sector can be explained by means of Fig. 6 . This figure presents two vertically connected markets. The top diagram represents the situation of the market for processed milk product, while the bottom one the market for unprocessed milk. To simplify exposition (and the diagram), we consider in the figure the situation where processing firms are acting collusively and therefore it corresponds to the situation where they act as a monopoly in selling (top panel) and a monopsony in buying (bottom panel).

The result of market imperfection is that affluent consumers pay more $\left(\mathrm{P}^{\mathrm{H}}\right)$ for the pasteurised milk and the firms produce less $\left(\mathrm{Q}^{\mathrm{H}}\right)$ than in perfect competition (where the demand $\mathrm{D}^{\mathrm{H}}$ intersects the marginal cost of the processing firms $\mathrm{MgC}^{\mathrm{H}}$ ).

The situation in the unprocessed milk market comprises two differentiated submarkets: (1) the market for milk to be pasteurised and (2) the informal milk market. For (1), the result of the "monopsony"14 situation is that processors demand less milk $\left(\mathrm{Q}^{\mathrm{MH}}\right)$ and pay a low price for it $\left(\mathrm{P}^{\mathrm{MH}}\right)$ and dairy producers market the bulk of their milk in the informal market, where they sell $\mathrm{Q}^{\mathrm{L}}$ at a price $\mathrm{P}^{\mathrm{L}}$, which can be higher or lower than the price paid by the formal sector, depending on factors such as the price elasticity of the demand and supply for low quality milk $\left(\mathrm{D}^{\mathrm{L}}, \mathrm{S}^{\mathrm{L}}\right)$, and the total amount of milk produced.

\section{Processors' potential oligopoly power}

A problem for the estimation of the degree of market power is the lack of available data to estimate the elasticity of supply of the competitors firms required in the Landes and 

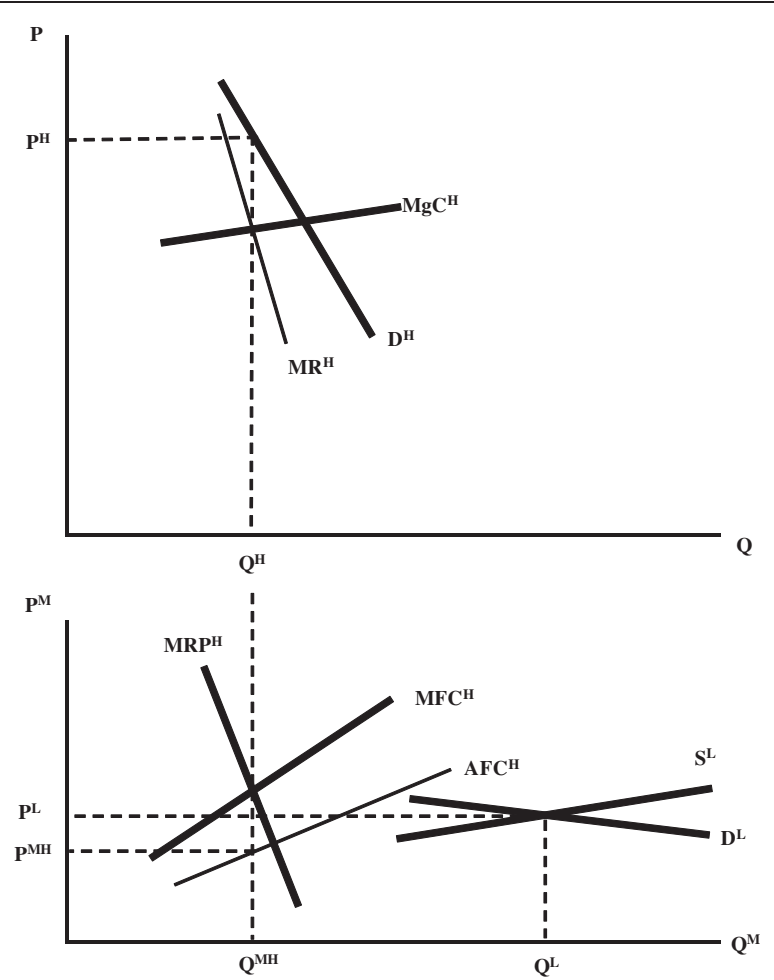

Fig. 6 Malawi dairy market under imperfect competition situation

Posner (1981) method. Due to this, Table 3 presents the values of L conditional to possible values of the supply elasticity of competitors. In the presence of idle capacity one would expect the supply elasticity to be around one or higher as the firms would not be constrained in terms of expanding production in response to an increase in price. Therefore, we assume several values for the elasticity of supply ranging from 0.5 to 2 . In addition, based on data from SHMPA and CREMPA and interviews with processors, the market shares at the retail level for pasteurised milk have been constructed. The focus is on pasteurised milk because for other dairy products it is considered that the

Table 3 Lerner index $(L)$ for the processing companies conditional to several competitor supply elasticities

\begin{tabular}{|c|c|c|c|c|c|c|}
\hline \multirow[t]{2}{*}{ Companies } & \multicolumn{5}{|c|}{ Supply elasticity 2/ } & \multirow{2}{*}{$\begin{array}{l}\text { Shares (\%) } \\
20123 /\end{array}$} \\
\hline & 0.5 & 0.8 & 1 & 1.5 & 2 & \\
\hline Processor 1 & 0.24 & 0.19 & 0.17 & 0.13 & 0.11 & 22.4 \\
\hline Processor 2 & 0.04 & 0.03 & 0.03 & 0.02 & 0.02 & 3.8 \\
\hline Processor 3 & 0.46 & 0.38 & 0.34 & 0.27 & 0.22 & 39.7 \\
\hline Processor 4 & 0.05 & 0.04 & 0.03 & 0.03 & 0.02 & 5.1 \\
\hline Processor 5 & 0.03 & 0.02 & 0.02 & 0.01 & 0.01 & 2.9 \\
\hline Processor 6 & 0.28 & 0.23 & 0.20 & 0.16 & 0.13 & 26.1 \\
\hline
\end{tabular}

Source: Own elaboration based on information provided by dairy Malawian processors

Notes

1/Market demand elasticity used for the exercise was -0.564 (highest quintile in urban areas) computed by Ecker and Qaim (2011)

2/Supply elasticity of all the competitors together

3/It refers only to the market shares on pasteurised milk sold at the retail level for 2012 
existence of extensive imports prevents market power being exerted by domestic processors.

Under our assumptions, the results of Table 3 seem to indicate that there is no clear indication of market power by processors from the product side (pasteurised milk market) as reflected in the Lerner index.

\section{Processors' potential oligopsony power}

Whilst no formal tests have been undertaken, previous analysis has provided hints that the processors have some degree of market power in the input markets. For example, CYE Consult (2009) speculated that with the low volume of milk being supplied, it was difficult to understand why the same price was paid throughout the year to dairy farmers, when common practice in other parts of the world was to increase the price paid to farmers when production fell due to seasonal factors. This paradoxical result can be partially explained by the fact that processors have the possibility to use reconstituted imported milk powder in their production of dairy products. This could make the derived demand for milk for processing more elastic and reduce the demand for domestic milk if producers sought higher prices. ${ }^{15}$

Another reason for speculating that some degree of market power exists in the input market is the fact that according to OVOP (2011) one of the reasons for the establishment of the cooperative is to negotiate better prices with processors. Although this is mentioned in terms of rewarding the production of higher quality milk, it also may imply that the processors have the capacity to set prices.

More generally, a number of conditions need to be met in order for an oligopsonistic situation to emerge. Two of these, are that the supply of milk to the processors must be elastic and that they control a significant share of the market. In terms of supply elasticity, Revoredo-Giha et al. (2013) estimated that the long term supply elasticity is in fact elastic (and equal to 1.45). They hypothesise that part of the reason for this is that as a sizeable proportion of milk enters the informal market then a price rise by processors is likely to move milk from the informal into the formal market, implying an elastic response.

However, one of the reasons hypothesised for the elastic supply of milk to processors, the large informal market, is actually likely to preclude the processors from having real market power as they do not control a significant enough share of the market. This is shown in Fig. 7, which uses official statistics to estimate the split in raw milk supplies over time between the formal and informal markets. The processors are clearly not the main buyers of milk in Malawi, as the informal market receives over $60 \%$ of the milk produced.

Further, the evidence provided by Revoredo-Giha et al. $(2013,2015)$ in relation to the supply response of milk in Malawi indicates that the role of the processing sector in setting prices, is likely to be barometric (Scherer and Ross 1990), with the informal sector being a follower. This is consistent with the fact that the informal sector is not an organised sector but a number of small traders.

The fact that the processors have idle capacity but not market power appears to support the argument that the two development strategies are indeed contradictory at the present time. However, the data underlying Fig. 7, also allows further insights into this 


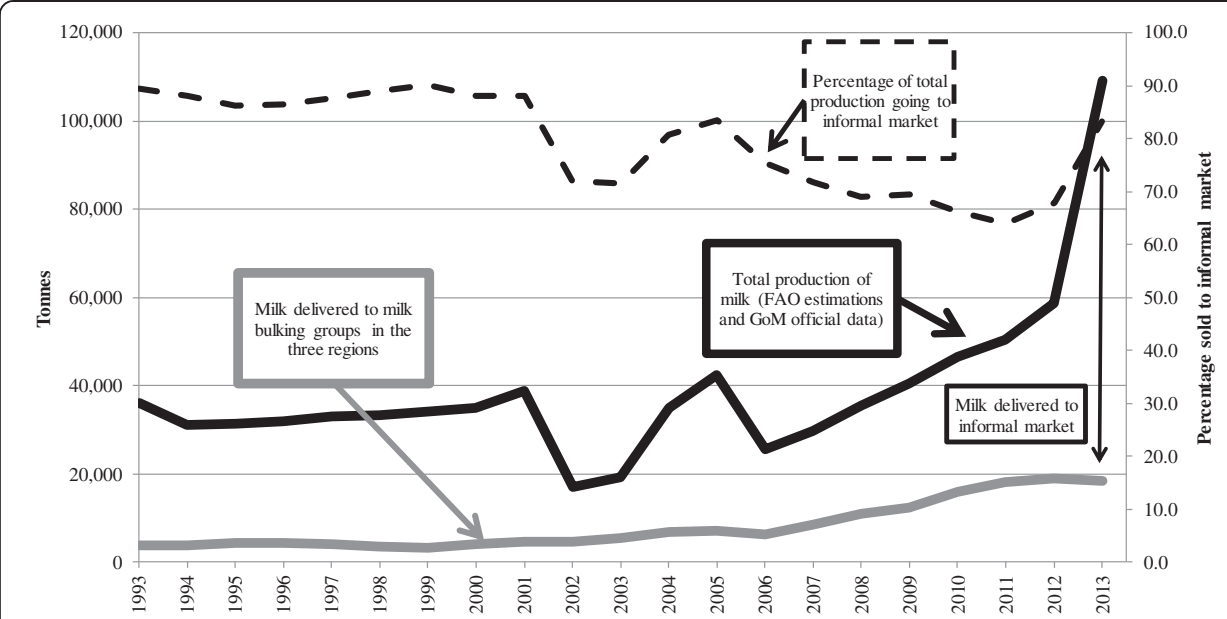

Fig. 7 Total production of milk, milk delivered to processors and percentage of milk outside the formal market

issue. The scale of milk production (even discounting the very high estimates for 2013) and the amount of milk that is currently collected by the milk bulking groups for the formal market (processors and microprocessors) suggests that actually the two studied strategies could coexist, even with the processing sector operating at full capacity. This would be the case if milk destined for the informal market could be captured by milk bulking groups allowing them to supply an increasing demand from both processors and microprocessors. However, under the current circumstances where the bulking groups are not attracting this milk, there is an incompatibly between the two strategies as expansion of micro processing reduces the milk available to processors.

\section{Conclusions}

The purpose of this paper was not only to portray the situation of the Malawi dairy industry using the most recent available information, but also to show the need of international donors to coordinate their development plans. This case study shows the need for detailed discussion on the actions to be taken within a country including the underlying rationale, because they do guide the allocation of scarce resources.

In the particular case of the dairy sector in Malawi, the results indicate that it is very unlikely that the processing industry has either market power in both the output and input market (milk) and therefore a strategy such as the one carried out by USAID of reinforcing the formal market seems to be more consistent with the situation of the dairy industry. Furthermore, given the current extent of milk collection by the milk bulking groups the second strategy being followed in Malawi, the encouragement of micro-processing actually conflicts with the reinforcing of the formal market.

An additional conclusion from the analysis is the need to "formalise" the informal market. If statistics on production are correct, then a large proportion of the milk produced in Malawi is distributed without any sort of quality control. As the milk is sold raw (without pasteurisation) nothing in the current system ensures that it will be of good quality because all the quality controls in Malawi are made at the level of the milk bulking groups. 
To add further weight to the importance of analysing the structure of domestic markets when considering development strategies, it should be noted that the Malawian dairy sector is not an isolated case. There are a number of other supply chains, born from industrialisation processes, which are characterised by high levels of idle capacity and the production of a narrow range of products. These lead to high prices for consumers with important implications not only for economic development, but also for food security (for example see Gorton and White 2007).

Finally, it should be noted that other strategies are being considered by developing countries (see for example, Jiaqi and Lambert 2002 or Omore et al. 2004). These include the creation of "small-scale dairy supply chains" (i.e., through small-scale marketing and processing facilities) as a way to contribute significantly to employment in rural, peri-urban and urban areas. This approach aims to improve the quality of milk destined for the informal markets. The existence of these other strategies increases the need for discussion as to whether or not investing in improving ineffective supply chains is the right approach to follow. However, as argued within this paper, whichever development approach is followed, it needs to be based on solid evidence and the impacts of different possible strategies need to be evaluated through the use of a range of important development indicators.

\section{Endnotes}

${ }^{1}$ Milk bulking groups are operated by farmers' associations.

${ }^{2}$ Note that estimated yields (milk production per cow) are a result of the estimation of the number of dairy animals by FAO and the estimation of the total production of milk by the Government of Malawi. During the period 1976 to 2011 yields were on average $4591 \mathrm{Hg} /$ cow with a coefficient of variation of $2.7 \%$, in 2012 yields were on average $5525 \mathrm{Hg} /$ cow and in $20139091 \mathrm{Hg} / \mathrm{cow}$. Whilst the increase in the number of cows might be explained by the Presidential Initiative "One Cow per Family" launched in April 2013 and was supported by donors such as Heifer International, the massive increase in production and in yields in 2013 is far more difficult to explain.

${ }^{3}$ It is important to note that milk that is rejected from the formal channel is sold to vendors in the informal market. According to Chimbaza (2010) a high percentage of the milk sent to the formal channel is rejected due to quality (estimated at $17 \%$ ).

${ }^{4}$ The higher price received in the informal market than in the formal market was also reported by Barnard (2007).

${ }^{5}$ The exchange rate in 2004 was 1 US\$ = 108 Malawian Kwacha (MK).

${ }^{6}$ Excess capacity is commonplace in African manufacturing being repeatedly mentioned in the development economics literature (e.g., Mytelka 1989 and Mazumdar and Mazaheri 2003 for several Sub-Sahara African countries).

${ }^{7}$ According to CYE Consultant (2008) a lot of the machinery used by the processors is out of date and needs replacing. This is especially true with Northern Dairies where some of the processing machinery is over fifty years old.

${ }^{8}$ According to Fintrac Inc (2008) Malawi imports all of its milk powder requirements, averaging about $2000 \mathrm{MT}$ per year over the past five years, the equivalent of 15.3 million litres of whole milk. The 2007 import data showed a steep decline to $1384 \mathrm{MT}$, attributed to the unprecedented price increases for milk powder, which in the case of the EU price of whole milk powder peaked in September 2007 at US\$5,500 per MT. 
${ }^{9}$ Note, however, that the powder milk avoids costs in terms of quality and other marketing costs associated with the milk collection.

${ }^{10}$ This is a working paper produced by the Overseas Development Institute (ODI) jointly with JICA. The paper reviews JICA's strategy producing a strengths, weaknesses, opportunities and threats (SWOT) analysis and comparing it with other donors' strategies, unfortunately, USAID strategy in Africa is not included in the paper.

${ }^{11}$ In order to maintain the discussion in simple terms and focused on the donors' strategy, we abstract from the role of imports of milk powder in the Malawi dairy market.

${ }^{12}$ It should be evident that the issue of market power is a necessary condition but not sufficient to prefer one alternative strategy to the other. That decision will need to be based on the consideration of multiple aspects each of which would need to be 'weighted'. These aspects could be: employment generation; multiplier effects on the wider population; sustainability of the strategy in terms of, whether it will generate resources that can be reinvested to replace the capital (at the least); etc.

${ }^{13}$ If time series were available the degree of market power could be studied by the approach presented in Schroeter (1988) or Azzam and Pagoulatos (1990).

${ }^{14} M R P^{H}$ denotes the derived demand for milk by processors, $M F C^{H}$ is the marginal cost of the milk producers serving the high quality market and $A F C^{H}$ is the average cost of those producers.

${ }^{15} \mathrm{~A}$ related issue can be found in the discussion of whether the monetisation of milk powder as part of USAID's Programme of Food for Peace would distort the Malawian dairy domestic market (Fintrac Inc 2008). Thus, on the one hand, Fintrac Inc., in their report produced for USAID to provide guidance about what commodities should be monetised, stated that selling milk powder to processors would expand their production and reduce their prices with obvious benefit to consumers. On the other hand, Land O' Lakes made it clear that it did not support milk powder for monetization due to its possible effects on the domestic market.

Competing interests

The authors declare that they have no competing interests.

Author's contributions

CRG drafted the first version of the paper and proposed the analytical approach. The final draft and structure of the paper was the result of the discussion of both authors. Both authors read and approved the final manuscript.

Acknowledgments

This paper is part of the DFID/ESRC Growth Programme project Assessing the Contribution of the Dairy Sector to Economic Growth and Food Security in Malawi.

Author details

'Land Economy, Environment and Society Research Group, Scotland's Rural College (SRUC), King's Buildings, West Mains Road, Edinburgh EH9 3JG, UK. ${ }^{2}$ School Of Agriculture \& Food Science, Agriculture and Food Science, University College Dublin, Belfield, Dublin 4, Ireland.

Received: 15 June 2015 Accepted: 3 March 2016

Published online: 12 March 2016

References

Alston JM, Sexton RJ, Zhang M (1997) The effects of imperfect competition on the size and distribution of research benefits. Am J Agric Econ 79(4):1252-1265

Azzam A, Pagoulatos E (1990) Testing oligopolistic and oligopsonistic behaviour: an application to the US meat-packing industry. J Agric Econ 41(3):362-370

Baer W (1972) Import substitution and industrialization in Latin America: experiences and interpretations. Latin Am Res Rev 7(1):95-122 
Barnard J (2007) Milk enterprise development in Malawi - final report. Volunteer Service Organisation (VSO) Report, ESE/003, Lilongwe

Buck BJ (2008) Designing a private sector oriented dairy designing development program: experience from Africa. Land O' Lakes. Presentation for the FAO Asia Regional Dairy Conference. November, 19.

Chagunda MGG (2009) Historical perspective. In: Smallholder dairy production in Malawi: current status and future solutions, Scoping papers: optimising smallholder dairying project. SAC, Edinburgh

Chagunda MGG, Msiska ACM, Wollny CBA, Tchale H, Banda JW (2006) An analysis of smallholder farmers' willingness to adopt dairy performance recording in Malawi. Livestock Res Rural Dev 18:5

Chimbaza T (2010) Milk keeping quality in Malawi. In: Smallholder dairy production in Malawi: current status and future solutions, Scoping papers: optimising smallholder dairying project. SAC, Edinburgh

Chitika RJ (2008) Marketing channel choice: its determinants and evaluation of transaction costs in smallholder dairy farming in Lilongwe milkshed area, Malawi. Unpublished Master Thesis, Makerere University.

CYE Consult (2009) Value chain analysis of selected commodities institutional development across the agri-food sector (IDAF) - 9 ACP MAI 19. Final Report Request for services n²008/159774/1.

Department of Animal Health and Livestock Development (DAHLD) (2008) Annual livestock census. Ministry of agriculture and food security, Lilongwe, Malawi

Ecker O, Qaim M (2011) Analyzing nutritional impacts of policies: an empirical study for Malawi. World Dev 39(3):412428

Fintrac Inc. (2008) Best analysis - Malawi - Bellmon estimation studies for Title II (best) project. Publication produced for review by the United States Agency for International Development. December. Available online: http://pdf.usaid. gov/pdf_docs/Pnado944.pdf

Flemish International Cooperation Agency (FICA) (2011) Contribution on the dairy sector through farmers associations Malawi. Description of the project. Accessed online at: [http://www.fica.be/index.php?pid=1\&sid=\&sit=49] on August 2013.

Gorton M, White J (2007) The restructuring of agrifood supply chains in CEE and the CIS Overview and policy implications. Outlook on Agriculture 36, No 4: 237-246.

Gorton M, Dumitrashko ML, White J (2006) Overcoming supply chain failure in the agri-food sector: a case study from Moldova. Food Policy 31:90-103

Gow H, Swinnen J (1998) Up- and downstream restructuring, foreign direct investment, and hold-up problems in agricultural transition. Eur Rev Agric Econ 25:331-350

Imani Development Consultants (2004) Review of the Dairy Industry in Malawi, Report prepared for RATES Centre, Ethiopia.

Jiaqi W, Lambert JC (2002) Proceedings of the China-FAO regional Asian workshop on "small-scale milk collection and processing in developing countries. FAO, Rome

Kedrock B, Agar J (2007) Assessment of the SME Sector in Malawi in preparation for a development credit authority loan portfolio guarantee. Report prepared for USAID for the project Deepening Malawi's Microfinance Sector Project (DMS).

Kurokawa K, Tembo F, te Velde DW (2008) Donor support to private sector development in sub-Saharan Africa Understanding the Japanese OVOP programme. JICA-ODI Working Paper 290.

Kurwijila L, Bennett A (2011) Dairy development: institutions in East Africa: lessons and options. FAO, Rome

Landes WM, Posner RA (1981) Market power in antitrust cases. Harv Law Rev 94(5):937-996

Malawi Government (2008) Annual economic report. Ministry of economic planning and development, Lilongwe, Malawi

Malawi Investment Promotion Agency (MIPA) (2011) Investment opportunities on agriculture. Accessed at: [ http://www.malawi-invest.net/inves_opp_agri.html] on August 2013.

Mazumdar D, Mazaheri A (2003) The African manufacturing firm. Routledge, London and New York, 2003.

Munthali JTK, Musa FA, Chiwayula CLK (1993) Smallholder dairy development in Malawi. In: Kategile JA, Mubi S (eds) Proceedings of the workshop future of livestock industries in east and Southern Africa held at Kadoma Ranch Hotel, Zimbabwe 20-23 july 1992. International Livestock Centre for Africa, Addis Ababa

Mytelka LK (1989) The unfulfilled promise of African industrialization. Afr Stud Rev 32(3):77-137

Omore A, Cheng'ole Mulindo J, Fakhrul Islam SM, Nurah G, Khan MI, Staal SJ (2004) Employment generation through small-scale dairy marketing and processing: experiences from Kenya, Bangladesh and Ghana. FAO, Rome

One village one group (OVOP) (2011). Bvumbwe Dairy Farmers. Available online at: http://www.ovop.org.mw/group_ bvumbwedairy.html

Revoredo-Giha C, Chitika R (2014) Identifying barriers for the development of the dairy supply chain in Malawi. Available online at: https://cgspace.cgiar.org/bitstream/handle/10568/64975//dentifyingBarriers.pdf?sequence=1

Revoredo-Giha C, Arakelyan I, Chalmers N, Chitika R (2013) How responsive to prices is the supply of milk in Malawi? (No. 152214). Available online at: http://r4d.dfid.gov.uk/pdf/outputs/ESRC_DFID/60974_Milk_Supply_Malawi.pdf.

Revoredo-Giha C, Arakelyan I, Chalmers N (2015) Processors pricing and smallholders' milk supply response in Malawi: an application of the nonlinear autoregressive distributed lag model. In: Contributed paper at the 29th international conference of agricultural economists "agriculture in an interconnected world", Milan august 9-14., p 2015

Scherer FM, Ross D (1990) Industrial market structure and economic performance, 3rd edn., Houghton Mifflin

Schroeter JR (1988) Estimating the degree of market power in the beef packing industry. Rev Econ Stat 70(1):158-162

Winston GC (1974) The theory of capital utilization and idleness. J Econ Lit 12(4):1301-1320 